\title{
Iberismo versus americanismo nos esportes: \\ Uma análise do futebol na constituição sócio-histórica do imaginário latino-americano
}

\author{
Iberismo versus americanismo en el fútbol: \\ Un análisis sobre el lugar de los deportes en la construcción socio \\ histórica del imaginario latinoamericano
}

\author{
Iberism against Americanism: \\ An analysis of the place of football in the social and historical process of \\ Latin American imaginary
}

\author{
Bernardo Borges Buarque de Hollanda ${ }^{1}$
}

\begin{abstract}
Resumo
O artigo examina a discussão intelectual em torno da ideia de América Latina, com o objetivo principal de mostrar como tal debate se manifestou no âmbito do futebol profissional da região. O argumento proposto é o de que a concepção de uma unidade latino-americana encontrou especial dificuldade de construção identitária esportiva ao longo de sua história, mais precisamente entre fins do século XIX e o final do século passado. Se os territórios geográficos costumam atravessar períodos históricos que oscilam entre unidade e fragmentação, entre aproximação e distanciamento, entre identidade e diferença, o caso latino-americano chama a atenção pelas características particulares de sua herança colonial. Sem ser apenas uma dimensão do passado, tais influências se tornaram mais complexas no decorrer do século XX, quando a emergência dos Estados Unidos como potência hegemônica continental passou a ter efeitos decisivos na economia, na política e na cultura latino-americanas. $\mathrm{O}$ propósito do presente artigo é sugerir que, embora a hegemonia estadunidense seja inconteste em diversas esferas da vida coletiva na América Latina, tal presença não se deu de modo tão direto no âmbito dos esportes modernos, especialmente no que tange à prática do futebol profissional de alto rendimento, por meio de torneios intercontinentais de clubes e seleções nacionais. Nesse domínio, a alteridade permaneceu voltada para o outro lado do Atlântico, seja para a Grã-Bretanha, inventora e codificadora das práticas esportivas espetacularizadas, sejam para os países europeus latinos - França, Itália, Espanha e Portugal - que difundiram e influenciaram em termos institucionais e culturais os estilos e as técnicas de jogo na América do Sul.
\end{abstract}

Palavras-chave: América Latina; iberismo/americanismo; imaginário esportivo; torneios futebolísticos; identidades coletivas no futebol;

\footnotetext{
${ }^{1}$ Doutor em História Social da Cultura (PUC-Rio) e Pós-doutor pela Maison des sciences de l'homme (MSHParis). Filia-se à Escola de Ciências Sociais da Fundação Getúlio Vargas (CPDOC-FGV). E-mail: bernardobuarque@gmail.com; bernardo.hollanda@fgv.br.
} 

e-ISSN 2016/Atual: 2525-7870 | e-ISSN 2015/2016: 2447-018X

\title{
Resumen
}

Este artículo trata sobre la discusión intelectual que se hace sobre América Latina, cuyo objetivo principal es mostrar cómo este debate se expresa en el fútbol profesional de la región. Su hipótesis es de que la concepción de una unidad latinoamericana encontró dificultades a lo largo de la historia, en especial entre el final del siglo XIX y del XX. Si geográficamente los territorios suelen pasar por continuos periodos históricos de intercambios entre unidad y fragmentación, entre acercarse y alejarse, llama la atención el caso latinoamericano por las características específicas de su herencia colonial. No es solamente algo del pasado, las influencias se convirtieron más complejas en el transcurso del siglo $X X$, cuando la urgencia de Estados Unidos como una potencia hegemónica empezó a producir efectos económicos, políticos y culturales en los países latinoamericanos. En esta presentación, nuestra intención es sugerir que, aunque la hegemonía estadunidense esté presente en la vida colectiva de América Latina, esta presencia no ocurrió de manera tan directa en los deportes modernos, principalmente en la práctica del fútbol moderno de alto rendimiento, mediante torneos intercontinentales de los equipos y de las selecciones. En este sentido, la alteridad permaneció en el otro lado del Atlántico, sea para la Gran Bretaña, inventora y decodificadora de las prácticas deportivas, o para los países europeos, como Francia, Italia, España y Portugal, que influenciaron institucional y culturalmente los estilos y las técnicas de jugar en América del Sur.

Palabras clave: América Latina; iberismo/americanismo; imaginario deportivo; torneos de fútbol; identidades colectivas.

\begin{abstract}
The article deals with the intellectual discussion about the idea of Latin America, with the objective of showing how this debate is manifested in the context of the region's professional football. The argument we propose is that the design of a Latin American unit encountered difficulties regarding the construction of identity throughout its history, more precisely between the late $19^{\text {th }}$ century and the end of the last century. If the geographical territories often cross historical periods of continuous exchange between unity and fragmentation, approximation and distancing, the Latin American case draws attention to the particular characteristics of its colonial heritage. Without being only a dimension of the past, such influences became more complex throughout the $20^{\text {th }}$ century, when the emergence of the United States as a hegemonic power began to have decisive effects on Latin American economy, politics, and culture. Our purpose here is to suggest that, although USA's hegemony is uncontested in all contexts of collective life in Latin America, its presence was not directly felt regarding modern sports, especially in the practice of professional football, through intercontinental tournaments of clubs and National teams. In this context, the otherness remained focused on the other side of the Atlantic: either to the United Kingdom, responsible for inventing and making the rules of sports practices; or to Latin European countries - France, Italy, Spain and Portugal - that influenced in institutional and cultural terms the styles and playing techniques in South America.
\end{abstract}

Keywords: Latin America; Iberism/Americanism; sports imaginary; football tournaments; collective identities.

\section{Introdução}

O presente artigo examina a discussão intelectual em torno da ideia de América Latina. O objetivo principal é mostrar de que maneira tal debate repercutiu, direta ou indiretamente, no âmbito do futebol profissional da região. $\mathrm{O}$ argumento proposto é o de que, se todos os continentes passam por processos identitários que demarcam diferenças e semelhanças entre as nações vizinhas, a concepção de uma unidade da América Latina encontrou especial dificuldade de construção identitária ao longo de sua história, mais precisamente entre fins do século XIX e o final do século passado.

Se os territórios geográficos costumam atravessar períodos históricos contínuos de intercâmbio fronteiriço entre unidade e fragmentação, entre aproximação e distanciamento, o caso latino-americano chama a atenção pelas características particulares de sua herança 
colonial. Tais características se expressam por meio das múltiplas influências advindas das metrópoles colonizadoras, sobretudo Espanha, Portugal, Inglaterra e França.

Sem ser apenas uma dimensão do passado, tais influências se tornaram mais complexas no decorrer do século XX, quando a emergência dos Estados Unidos como potência hegemônica passou a ter efeitos decisivos na economia, na política, na sociedade e na cultura latino-americanas.

Nosso propósito aqui é sugerir que, embora a hegemonia estadunidense seja inconteste em todas as esferas da vida coletiva na América Latina, tal presença não se deu de modo tão direto no âmbito dos esportes modernos, especialmente no que tange à prática do futebol profissional de alto rendimento, por meio de torneios intercontinentais de clubes e seleções.

Nesse domínio, a alteridade permaneceu voltada para o outro lado do Atlântico, seja para a Grã-Bretanha, inventora e codificadora das práticas esportivas, sejam para os países europeus latinos - França, Itália, Espanha e Portugal - que influenciaram em termos institucionais e culturais os estilos e as técnicas de jogo na América do Sul.

Neste artigo, trata-se primeiramente de salientar a natureza dos debates intelectuais em torno da ideia de América Latina. No momento seguinte, pontua-se um histórico da criação de torneios esportivos entre clubes e selecionados nacionais de países situados na América Latina, a fim de mostrar o lento processo institucional de construção dessa identidade por meio dos esportes e por meio de um diálogo com a temporalidade e com o calendário futebolístico europeu. Por fim, conclui-se com um balanço acerca dos limites e das potencialidades de constituição de uma unidade latino-americana esportiva na conjuntura de princípios do século XXI.

\section{A construção da identidade latino-americana: continuidades e intermitências}

Desde o final do século XIX, a autoconsciência intelectual do ser latino-americano foi buscada por escritores como José Martí (1999), em Cuba, e José Enrique Rodó (1985), no Uruguai. No Brasil, é representativo o nome do médico Manoel Bomfim (1993), formulador em 1903 de uma crítica à condição parasitária vivenciada na região, em razão da mentalidade e das práticas coloniais legadas pelas metrópoles europeias. A este naipe de autores, se seguiu o mexicano José Vasconcelos (VERÍSSIMO, 2013), autor em 1925 do livro “A raça cósmica: missão da raça íbero-americana", que já preconizava um certo tipo de "utopia híbrida", mobilizadora do imaginário continental.

$\mathrm{Na}$ ambiência intelectual latino-americana, pode-se dizer que, de um lado, preponderou o "arielismo", expressão inspirada em um personagem sobrenatural da peça "A tempestade" 
(1611), uma das últimas obras de William Shakespeare. Tal corrente de pensamento se contrapunha às correntes modernizadoras e cientificistas, e apregoava um regresso ao passado ibérico. De outro lado, sobressaiu a vertente representada por Domingos Sarmiento (2010), na Argentina, que assestava suas bases contra a realidade provinciana do caudilhismo e colocavase em favor do alinhamento das antigas colônias hispânicas ao modelo norte-americano.

Expressão cunhada na França oitocentista, no período em que esta esteve sob o comando de Napoleão III, América Latina foi vulgarizada nos Estados Unidos da segunda metade do século XIX, de modo a identificar uma área geográfica ao sul do Rio Grande estadunidense, na fronteira com o México. A categoria surge após uma expedição científico-militar francesa ao México e sua cunhagem em livro data do ano de 1862. O "outro" americano deixava então de ser apenas contraposto à Europa e passava a mirar o território contíguo, situado ao sul do Equador.

Já em 1856 o poeta e diplomata colombiano José Maria Torres Caicedo contrastava América "latina" à "anglo-saxônica", em seu poema Las Dos Américas. Caicedo fundou sociedades intelectuais com vistas a aproximar os países latino-americanos, o que evidenciava tratar-se de um projeto político. Este, por sua vez, assentava-se em ideia antiga sobre a "raça latina", cunhada pelo francês Michel Chevalier em 1839, a fim de aproximar os falantes de língua francesa, espanhola, portuguesa e italiana. A aproximação agradava as elites criollas da América Espanhola, posto que estas tinham por característica o apreço pela cultura francófona (Burke, 2009, p. 159).

Em face disso, não demoraria para o termo ser colocado em contraposição à política panamericanista emergente nos Estados Unidos. O pan-americanismo, por sua vez, se intensificou na virada do século XIX para o século XX, com a emergência da hegemonia estadunidense, na busca por ampliar sua política expansionista e sua zona de influência internacional. O período foi marcado por guerras perpetradas pelos EUA, como a ocorrida contra a Espanha em 1898, na disputa por ilhas antilhanas do Caribe, tais como Cuba e Porto Rico.

Nessa época também, lemas expansionistas se tornaram bastante conhecidos, desde a divulgação da Doutrina Monroe, traçada em 1823 e retomada no início do século XX por Theodore Roosevelt - "A América para os americanos" -, na esteira da implantação da diplomacia do big stick, patrocinada pelo secretário de Estado americano James Blaine.

As dificuldades de consecução do projeto pan-americanista não foram poucas. Parte dos obstáculos decorreu das especificidades da cultura ibérica transplantada para o território americano. Iberismo e americanismo constituíram polos antitéticos, acionados por autores do 
pensamento social, na comparação contrastante com os modelos de desenvolvimento em cada região.

O contraponto também foi utilizado por políticos interessados em justificar a supremacia estadunidense, a partir do caso considerado bem-sucedido da colonização da América do Norte, fruto das "colônias de povoamento", tal como as denominou o economista francês Pierre Paul Leroy-Beaulieu. Já o endêmico atraso social da América Latina era explicado na chave da herança ibérica, que se materializou com base na experiência das suas "colônias de exploração", para remeter ao par antitético do mesmo Leroy-Beaulieu.

O norte-americano Richard Morse (1988) foi um dos pesquisadores que ousou pensar essa equação de forma menos previsível, sem contrastar de imediato um e outro e sem se valer de um princípio unidirecional. O brasilianista realçaria a herança ideológico-institucional contida nos conceitos de Ibero-América e de Anglo-América. A partir daí se debruçou sobre os valores específicos da América Latina, sua unidade supostamente racial, linguística e cultural, com a proposição de um princípio valorativo diferente para cada uma delas.

Isso porque a tradição explicativa salientava o atraso ibérico, com o predomínio do holismo, aniquilador das diferenças individuais. Já para os anglo-americanos consagrou-se a supremacia do individualismo de cunho protestante, cultivadora dos ideais democráticos, republicanos e constitucionais. Isto se plasmou na história norte-americana com o ideário das virtudes cívicas, da livre-iniciativa, da descentralização política e do liberalismo econômico.

Tratava-se de um país decantado pela intelectualidade cosmopolita, desde A democracia na América (1835), livro do francês Alexis de Tocqueville (1985). A decantação derivava da égide racionalista, materialista e liberal dos Estados Unidos, que incentivou a crença na autonomia do indivíduo sobre o todo. Já os países de herança hispânico-lusitana, calcados no legado histórico do catolicismo, formaram-se sob o princípio de um Estado mais incorporador, mais centralizador, baseado na vivência de uma comunidade hierarquizada.

Segundo Morse, esse traço, longe de ser um entrave, conferiu à experiência iberoamericana uma vantagem. Sua sociabilidade mais aberta, mais calorosa e mais fraterna permitiu-lhe inverter a tradicional desvalorização em face da alteridade estadunidense. A seu juízo, não se deveria conceber um EUA superior frente a uma América Latina inferior.

Ainda no plano das ideologias, sabe-se que o período entre guerras (1919-1939), intermediado pela "grande depressão", sob os danosos efeitos do crack da bolsa de Nova Iorque, valeu-se do uso da força física, com o emprego do poderio bélico-militar. Mas a preponderância belicista na política externa coexistiu com outras formas de domínio. A América do Norte passou a se relacionar com o hemisfério sul do continente a partir de uma mescla entre 
diplomacia e violência. $\mathrm{O}$ desenvolvimento dos meios de comunicação de massa em escala global permitiu um exercício de dominação mais sofisticado, sob a forma consagrada pela Escola de Frankfurt, a partir do conceito de indústria cultural.

Ao lado do debate sobre a indústria cultural, o continente conviveu com frequentes tensões na esfera política. Em constante ambiguidade com os governos dos EUA, os anos 1930, 1940 e 1950 assistem à emergência de presidentes e de ditadores latino-americanos que seriam denominados populistas por certa vertente de interpretação sociológica. No Brasil, em meio às vicissitudes históricas, o conceito de populismo foi elaborado por egressos da chamada Escola de Sociologia Paulista (MICELI, 2012).

Esses sociólogos sublinhavam as fragilidades do tipo de transformação capitalista na América Latina de meados do século XX, longe do tipo ideal erigido pelo marxismo com base na Revolução Industrial. Eles não negavam o advento das massas, mas argumentavam a indevida consideração das contradições sociais que subjaziam aos embates políticos. Procuravam chamar a atenção de que a retórica aliancista do nacionalismo tinha por efeito encobrir a questão fundamental do capitalismo. Esta se centrava nos conflitos de classe, no acirramento das disputas entre capital e trabalho, no papel histórico do operariado e nas rupturas mais drásticas do que as reformas realizadas por lideranças populistas.

A despeito dessas críticas acadêmicas inspiradas no contexto de debates marxistas da época, cujos pressupostos foram igualmente objeto nas últimas décadas de revisão e de análises mais acuradas (FERREIRA, 2001), os projetos de Lázaro Cárdenas no México, de Getúlio Vargas no Brasil e de Juan Domingo Perón na Argentina tornar-se-iam referências nacionalistas e trabalhistas importantes em seus respectivos países. Sua centralidade pode ser aferida nos desdobramentos históricos e nas linhagens lastreadas em suas sucessões.

Em lugar do sistema primário agroexportador, a industrialização seria a pedra de toque dos discursos governamentais. Acreditava-se que o processo industrial seria a força motriz da emancipação da região e, em vista disso, foi canalizada por líderes personalistas e por um sentimento nacional de cariz anticolonial, por contraste elementar às influências e às interferências externas.

Em âmbito institucional, após a Segunda Guerra mundial, vale dizer que a pesquisa local sobre a América Latina seria impulsionada pela criação da Comissão Econômica para a América Latina, em 1948. Conforme assinala o economista Celso Furtado, o órgão, vinculado às Nações Unidas (ONU), sofreu forte oposição de Washington em seus primeiros anos.

A CEPAL, sediada em Santiago do Chile, foi composta por uma geração de intelectuais latino-americanos, com formação técnica em economia e, ao mesmo tempo, com a preocupação 
desenvolvimentista que tencionava superar o atraso estrutural e conquistar a autonomia da região. No ambiente cepalino, pontificaram nomes como os do argentino Raúl Prebisch (DOSMAN, 2011), do brasileiro Celso Furtado (2007), responsáveis por traçar políticas públicas baseadas em estudos econômicos e em interpretações sociais articuladas à evolução histórica do continente.

América Latina compreende uma região territorial muito vasta, com mais de vinte milhões de quilômetros quadrados. O quadro regional encompassa a América do Sul, a América Central e as ilhas caribenhas. Trata-se de pelo menos três subconjuntos - o México setentrional, o istmo americano e o continente sul-americano - e de três línguas de origem colonial - o espanhol, o português e o francês. Estas, ao longo da história da colonização, solaparam as culturas pré-colombianas e as tradições étnico-culturais africanas.

Consoante a observação de Celso Furtado:

\begin{abstract}
“América Latina deixou de ser uma expressão geográfica para transformar-se em realidade histórica como decorrência da ruptura do quadro tradicional de divisão internacional do trabalho, dos problemas criados por uma industrialização tardia e da evolução de suas relações com os Estados Unidos, que, ao se transformarem em potência hegemônica mundial conceberam para a região um estatuto próprio, envolvendo um controle mais direto e ostensivo, e ao mesmo tempo requerendo crescente cooperação entre os países dessa área" (FURTADO, 2007, p. 32)
\end{abstract}

Em continuidade ao diálogo do desenvolvimentismo dos anos 1940 e 1950, mas também com críticas à leitura dualista então vigente, que fundamentou a industrialização por substituição de importação, surge em fins dos 1960 a geração responsável por lançar as bases da Teoria da Dependência, sob o impacto político de uma série de acontecimentos. Entre os de maior monta, pode-se citar a Revolução Cubana, a Aliança para o Progresso, o Peace Corps do presidente Kennedy e os golpes militares apoiados pelos EUA.

O debate intelectual dessa conjuntura seria enriquecido em 1970, quando o historiador chileno Enzo Faletto e o sociólogo brasileiro Fernando Henrique Cardoso publicam o ensaio Dependência e desenvolvimento na América Latina (2004). Nele, os autores procuram desfazer a ilusão da possibilidade de quebra real do modelo dicotômico centro-periferia. A contrapelo, os autores propõem desenvolvimentos regionais integrados entre os diversos países latinoamericanos, de modo a constituir uma alternativa concreta à voragem da divisão internacional do trabalho e ao domínio inelutável do grande capital sobre os mercados nacionais.

A radicalização foi uma constante à época, com extremismos de ambas as partes, em meio à implantação de regimes ditatoriais e discricionários que se prolongariam no poder. Os discursos e as práticas estiveram às voltas com processos revolucionários no Caribe - ilha de 
Cuba -, com movimentos insurrecionais na América Central - Nicarágua e Guatemala -, com projetos reformistas e golpistas na América do Sul - Argentina, Brasil, Chile, Peru e Uruguai. Assistiu-se a um período de quase indistinção entre militância político-ideológica e produção do conhecimento científico, sobretudo nos quadros das Ciências Sociais.

Talvez o livro mais emblemático dessa geração tenha sido assinado pelo escritor uruguaio Eduardo Galeano. As veias abertas da América Latina (1980), cuja primeira edição é de 1971, tornou-se tanto um libelo de libertação quanto um estudo alentado, consubstanciado em dados demonstrativos e na crença da espoliação sistemática a que foi submetida a região, no decorrer dos séculos de colonização e independência.

Em uma visada panorâmica, deve-se também destacar a contribuição da literatura na constituição do imaginário latino-americano do período. A influência literária se manifestou desde pelo menos o século XIX, quando sua função é não apenas ficcional como igualmente fundacional, sendo constitutiva da conformação da história e da identidade de cada país da região (SOMMER, 2004; SCHWARTZ, 2013).

$\mathrm{Na}$ fase contemporânea, durante a segunda metade do Novecentos, ocorreu o chamado "boom latino-americano", com a afirmação da literatura por meio de escritores do porte do colombiano Gabriel Garcia Marques, do peruano Manuel Scorza, do mexicano Juan Rulfo, do cubano Alejo Carpentier, do guatemalteco Miguel Ángel Asturias e da uruguaia Cristina Peri Rossi, entre outros. A crítica internacional avalizou a obra destes escritores e deu-lhe então a alcunha de "realismo mágico".

Tal corrente literária foi responsável pela projeção da América Latina no quadro da cultura letrada mais cosmopolita e obteve repercussões positivas na Europa e nos Estados Unidos. Publicado originalmente em 1967, Cem anos de solidão, de Garcia Marques, foi uma das obras de maior impacto editorial. Junto à projeção da literatura latino-americana, o romance levou o autor à conquista do Prêmio Nobel em 1982, o que lhe inspirou o discurso "A solidão da América Latina".

\section{O imaginário esportivo e a construção da identidade futebolística na América Latina}

O enquadramento histórico feito até aqui frisou o grande poder de influência estadunidense sobre o conjunto heterogêneo dos países latino-americanos. Não obstante, é válido apontar a existência de singularidades da relação entre os EUA e a América Latina no que se refere à cultura esportiva, em geral, e à cultura futebolística, em particular.

Sabe-se que a introdução e a implantação dos esportes modernos na América Latina durante a segunda metade do século XIX e o início do século XX decorreram da atuação 
econômico-cultural da Grã-Bretanha imperial sobre a região. A codificação e a irradiação de uma série de práticas esportivas conformadas ao ideário de modernidade e de civilização foram as expressões mais claras desse fenômeno.

A influência da Inglaterra, em pleno período vitoriano, foi notada de maneira direta e indireta. Em muitos casos, as modalidades de esporte chegaram pelos portos e pelas vias férreas às cidades latino-americanas por intermédio da ação de outros contingentes europeus. Enquanto engenheiros ingleses introduziam as práticas esportivas no continente americano, as nações da Europa continental, por seu turno, também praticavam esportes modernos como o futebol, por exemplo.

Ao assimilar hábitos e gostos dos países britânicos, introduziram-nos, por sua vez, em outras regiões do globo. Os países platinos, Argentina e Uruguai, destacaram-se nesse processo tanto a absorção das atividades físicas inventadas e codificadas na Grã-Bretanha, quanto a filtragem de seus valores morais - raça, fibra, elegância -, conforme desenvolve de maneira exemplar o antropólogo argentino Eduardo Archetti.

Um dos fatores explicativos para a criação de clubes esportivos na América Latina se deveu ao maciço êxodo de emigrantes europeus que saíram de Itália, Espanha e Portugal, entre outros, para radicar-se no continente americano. O historiador inglês Bill Murray sintetiza com propriedade esse fenômeno:

No fim do século XIX, a economia e o futebol se expandiram nas regiões litorâneas meridionais da América do Sul, principalmente nas grandes cidades situadas no estuário do rio da Prata: Buenos Aires e Montevideo. Nessa região, marinheiros e operários britânicos, principalmente das estradas de ferro, jogavam futebol na década de 1860. Vinte anos depois, surgiram diversos times, alguns muito conhecidos até hoje. Logo no início do século XX, a influência dos britânicos foi substituída pelos imigrantes do Sul da Europa, sobretudo italianos. Porém, os times com nomes britânicos negaram-se a trocá-los quando os italianos assumiram o controle. (MURRAY, 2000, p. 55)

Assim, a introdução do futebol na América do Sul fez com que a zona de influência dos Estados Unidos fosse limitada do ponto de vista da cultura esportiva. País poliesportivo, em que se destacaram atividades como o beisebol - surgido em 1839 -, o futebol americano distinto do soccer e adaptado do rúgbi em 1869 -, o basquete - criado em solo estadunidense em 1891 - e o hóquei, os EUA influenciaram a região do Caribe e das Antilhas (ECHEVARRÍA, 2004) e apenas pontualmente os países do Cone Sul. Segundo o historiador inglês Peter Burke, no artigo "Futebol versus críquete no Novo Mundo" (2009), o Exército norte-americano foi o introdutor do beisebol em Cuba e na República Dominicana em fins do século XIX. 

e-ISSN 2016/Atual: 2525-7870 | e-ISSN 2015/2016: 2447-018X

Sendo assim, a "criolização" da prática esportiva, ou seja, a hibridação de que falava Eduardo Archetti para tratar do polo e do futebol na Argentina (2003; TOLEDO, 2009), com o processo de assimilação pelas elites nativas de um fenômeno desportivo-cultural britânico, manifestou uma hegemonia em direção inversa. Quando se trata do território americano, isto favoreceu até certo ponto um pan-americanismo às avessas, como preconizava o brasilianista Richard Morse.

Este ponto é desenvolvido pelo historiador uruguaio Andrés Morales:

\begin{abstract}
El panamericanismo por un lado y el hispanoamericanismo por el otro, a veces enfrentados, a veces juntos, eran dos formas distintas de construir identidad nacional. En los discursos del fútbol, ambas posturas están muy presentes a la hora de narrar las copas y campeonatos ganados. El fútbol es apropriado como una tradición más en este período y en los discursos del triunfo se comenzaba a construir la idea de que era lo que hacía los uruguayos a los habitantes de la República. Es en el Ariel, de José Enrique Rodó, que hemos encontrado la influencia más grande de los discursos que giran alrededor de las victorias.
\end{abstract}

En la conquista de 1924 se construye la idea de que um equipo formado por hispanolatinos, fundamentalmente conformado por jugadores de origen español e italiano, había mostrado superioridad y había vencido a representaciones nacionales de países del tronco anglosajón como Holanda, Estados Unidos o Suiza. Con orgullo se decía que el equipo que había conquistado la medalla de oro hablaba en español. En 1928, la construcción de la identidad se realiza en círculos concéntricos. Con los triunfos contra Holanda y Alemania se parte una vez más de la idea de la superioridad de lo hispano-latino sobre lo anglosajón en el fútbol. Pero luego de derrotar a Italia (en donde el enfrentamiento es tomado como un choque entre dos potencias del fútbol latino), la alteridad básica pasa a ser de América contra Europa. (MORALES, 2013, p. 202)

A seleção de futebol dos EUA chegou a participar de algumas edições das Copas do Mundo na primeira metade do século XX, a exemplo de 1930 no Uruguai e de 1950 no Brasil. Contudo, é somente no curso dos anos 1970, em função da popularização planetária do futebol, que o universo esportivo norte-americano reconhece o valor do soccer e passa a investir financeiramente na modalidade, por meio de clubes internacionalizados, como o Cosmos de Nova Iorque. Nos anos 1990, o país, ao abrigar cada vez mais atletas de origem latina, aceita incorporar o soccer institucionalmente e conquista o direito de organizar, pela primeira vez, uma Copa do Mundo em seu território.

É possível destarte propor a inversão do par estrutural centro-periferia. Enquanto nas relações internacionais polarizaram-se as relações entre os EUA e a América Latina, a condição periférica latino-americana teve de ser relativizada na ambiência do futebol. Ao menos na América do Sul, a alteridade fundamental foi constituída face ao controle institucional do futebol pela Europa continental. Com o advento da francófona FIFA, em 1904, o 
relacionamento das entidades esportivas sul-americanas teve de passar pela mediação política de países como França e Itália, entre outros.

Primeiramente, até os anos de 1920, os encontros futebolísticos se deram em decorrência das excursões de times e selecionados, que cruzaram o Atlântico, de uma costa a outra deste oceano. Conforme pontua novamente Murray: “O primeiro time estrangeiro a excursionar pela América do Sul foi o Southampton, em 1905. Venceu todos os cinco jogos disputados na Argentina, sofrendo apenas três gols. O Nottingham Forest, no mesmo ano, venceu todos os sete jogos, sofrendo apenas um gol" (2000, p. 63).

Em seguida, o processo se expandiu com a criação de competições de magnitude internacional, como a Copa do Mundo da FIFA, a partir de 1930. Como sabemos, esta se autonomiza da modalidade amadorística que vigia nos Jogos Olímpicos e cria seu próprio torneio internacional. A Taça do Mundo, evento quadrienal, enseja o predomínio na alternância da supremacia técnica que confrontava as "escolas" europeia e sul-americana, conforme se dizia no jargão jornalístico da época. Em sua esteira, entre 1931 e 1933, Uruguai, Argentina, Brasil e Chile profissionalizam em cadeia seu futebol.

O imaginário futebolístico, tanto o de clubes quanto o de seleções, foi construído assim em um sentido dialógico e em uma ordem de escala crescente: do local ao nacional; deste ao continental; e este, por sua vez, até a esfera internacional. Na América do Sul dos anos 1910, o conhecimento mútuo dos selecionados nacionais se intensificou com a organização de torneios disputados entre países vizinhos.

São exemplos dos confrontos vicinais a Taça Bernardo O’Higgins (Brasil - Chile), a Taça Rio Branco (Brasil - Uruguai), a Copa Júlio Roca (Brasil - Argentina) e a Taça Osvaldo Cruz (Brasil - Paraguai).

No pós-primeira Guerra mundial, a participação sul-americana na modalidade futebolística dos Jogos Olímpicos se destacaria, positiva e negativamente. Em termos positivos, o destaque foi o bicampeonato uruguaio em 1924 e 1928, contra Suíça e Argentina, respectivamente. Já nas Olímpiadas de 1936, um incidente na prorrogação da partida de quartas de final do Peru, único representante da América do Sul, contra a Áustria, gerou uma briga generalizada. Jogadores austríacos entraram em confronto com torcedores peruanos, que invadiram o campo no estádio do Hertha Berlin (DIETSCHY, 2010, p. 248).

Eliminado do torneio pelo comitê organizador, o selecionado peruano e todos os atletas dessa nacionalidade retiraram-se da competição, sob as ordens do general Benavides, então presidente da República. O caso desencadeou uma série de litígios diplomáticos entre os 
dirigentes da Federação de Futebol do Peru e os membros do Comitê Olímpico Internacional, com ameaças em Lima aos consulados de Alemanha e Áustria.

Afora isso, cumpre reconhecer que os Jogos Olímpicos não chegariam a despertar grande interesse de parte das seleções sul-americanas. Isto pode ser inferido se for observado que a Seleção Brasileira, por exemplo, estreou no futebol olímpico apenas em 1952, nas Olimpíadas de Helsinque, e até as Olimpíadas Rio 2016 nunca havia obtido uma medalha de ouro na modalidade (GIGLIO, 2013).

Na segunda metade do século XX, outra competição importante ocorreu no interior dos Jogos Pan-americanos, cuja primeira edição teve lugar em Buenos Aires, no ano de 1951. Além disso, a partir de 1956, a Taça do Atlântico, sediada no Rio, colocou em disputa o conjunto destes selecionados. Tais jogos permitiram certo trânsito de jogadores e de técnicos, além dos estilos de jogos.

Um de seus efeitos negativos foi o crescimento das rivalidades no âmbito esportivo, potencializadas pelas relações vicinais. Provocações governamentais, polêmicas entre jornalistas, brigas de jogadores com torcedores, atos como queima de bandeiras e insultos racistas deram a tônica de algumas partidas dos torneios sul-americanos. Após desentendimentos sucessivos, Argentina e Brasil, por meio de suas entidades representativas, ficaram dez anos sem assistir à disputa entre seus selecionados (1946-1956).

Em chave positiva, podemos ponderar que o circuito de campeonatos também trouxe benefícios. Estádios de maior porte foram construídos, ainda que sob o manto das delicadas relações entre futebol e política (REIEN, 2015). Na Argentina, o general Agustín Justo contribuiu para a construção do estádio Monumental, em 1938, que teve o apoio também da municipalidade portenha. Às expensas do governo, já sob a égide do peronismo, na década seguinte foi inaugurado o estádio do Racing, em Avellaneda, para 60 mil torcedores, batizado com o nome do presidente da República, Perón (GAFFNEY, 2008; HÉMEURY, 2013).

Em campo, o contraponto com o futebol europeu, por exemplo, deu origem à “diagonal”, uma variante latino-americana do WM, modelo tático desenvolvido na Europa e visto como racional na estratégia de distribuição dos jogadores no espaço do campo. A variação deu a marca do estilo latino-americano durante pelo menos trinta anos, desde o título uruguaio nas Olimpíadas de 1924. A circulação interna de técnicos e jogadores, ao menos na América do Sul, foi um fator contribuinte para isto.

Como exemplo, lembre-se a greve de jogadores na Argentina em 1948 (FRYDENBERG, SAZBON, 2015), seguida do êxodo dos argentinos para o futebol colombiano em sua fase de ouro, incluindo Alfredo Di Stéfano, recrutado pelo Millonarios da Colômbia; evoque-se o 
paraguaio Fleitas Solich, treinador que atuou no Brasil nesse mesmo período; e citem-se atletas como os atacantes Leônidas da Silva, Domingos da Guia e Heleno de Freitas, que, em momentos distintos, tiveram passagens por clubes do futebol platino.

Antes da intensificação da circulação de futebolistas, de treinadores e de ligas, os confrontos binacionais, acima mencionados, foram o embrião do Campeonato Sul-Americano. Disputado de 1916 em diante, ele passou a se chamar de Copa América em 1975, sendo o homólogo da Eurocopa. Enquanto na América do Sul a competição de seleções nacionais ocorre durante a Primeira Guerra mundial, na Europa seu correspondente em escala continental só seria criado em 1960.

A entidade organizadora do evento foi a confederação sul-americana, que congregou as federações de futebol de cada um desses países do cone sul. Somados à Bolívia, à Colômbia, ao Peru, ao Paraguai e à Venezuela, estes entes esportivos deram origem à CONMEBOL, formada por dez países. Para ampliar o raio de ação, desde o início dos anos 1990 mais dois países de outras regiões têm sido convidados, sendo o México o mais frequente deles. O México, país sob a zona de influência estadunidense, integra desde 1982 a CONCACAF, reunião por sua vez de países da América do Norte, Central e Caribe, mais as três Guianas.

No que concerne aos espectadores de futebol, os deslocamentos de torcedores foram multiplicados pelos torneios continentais e mundiais de seleções nacionais. A final da Copa do Mundo de 1930, disputada entre Uruguai e Argentina em Montevidéu, foi acompanhada por mais de noventa mil espectadores. Deste total, cerca de vinte mil eram argentinos. Valendo-se de navios, milhares de portenhos cruzaram o Rio Prata, para assistir à decisão.

A despeito da pedagogia civilizatória encarnada nos princípios esportivos modernos, os jogos de seleções e de clubes foram marcados por hostilidades endêmicas, virulentos confrontos e graves tensões, dentro e fora do gramado. É novamente Bill Murray quem documenta:

\footnotetext{
Na América do Sul, na década de 1920, os policiais precisavam cavar fossos e fazer cerca com arame farpado para manter os torcedores afastados do campo. Os estádios eram superlotados e os torcedores adoravam invadir o campo para comemorar com o jogador que marcava o gol, por isso a precaução. Mas também havia casos de violência contra juízes e jogadores. (MURRAY, 2000, p. 88)
}

Os torcedores de clubes sul-americanos, salvo amistosos e torneios pontuais, tiveram de esperar os anos de 1960 para assistir ao surgimento de um campeonato continental em âmbito clubístico, chamado Taça Libertadores da América (CASTRO, 1988). Com tal competição, não apenas os clubes sul-americanos e suas respectivas torcidas começaram a circular no continente com maior regularidade, como o evento permitiu o confronto dos seus campeões com os clubes 
europeus vitoriosos da Eurocopa. A relação estrutural - América do Sul versus Europa - foi assim realimentada na segunda metade do século XX, passando do nível dos selecionados nacionais para aquele relativo às agremiações clubísticas.

Ao longo de 55 anos de existência, a Taça Libertadores da América permitiu a projeção do nome de clubes como o Peñarol e o Nacional, do Uruguai; o Olímpia e o Cerro Portenho, do Paraguai; o Colo-Colo, a Universidade Católica, a Universidade de Chile e o Cobreloa, do Chile; o Once Caldas, o América de Cali, o Atlético Nacional e o Deportivo de Cali, da Colômbia; a LDU e o Emelec, do Equador; o Universitário e o Sporting Cristal, do Peru; o Bolívar, da Bolívia, entre muitos outros, de um total de 168 equipes que já disputaram esta taça.

A lista pode ser ampliada, quando se consideram os times argentinos e brasileiros. Quanto aos clubes argentinos, listem-se como mais reconhecidos no continente o Independiente, o Racing, o Boca Juniores, o River Plate, o Estudiantes de la Plata, o Argentino Juniores, o Vélez Sársfield, o Newell's Old Boys e o San Lorenzo, concentrados nas cidades de Buenos Aires e La Plata.

Quanto ao Brasil, destaque para clubes como o Santos, o Cruzeiro, o Flamengo, o Grêmio, o São Paulo, o Vasco da Gama, o Palmeiras, o Internacional e o Corinthians, provenientes das regiões sul e sudeste do país, que chegaram às fases decisivas e conquistaram títulos. Incorporados mais recentemente à competição, os mexicanos destacaram-se por meio de clubes como o América, o Tigres e o Cruz Azul. Além destes três, oriundos da capital, vale menção para o Chivas, de Guadalajara (VITAL, 2014).

\section{Considerações finais}

A descrição feita acima nos dá elementos para concluir com algumas reflexões de ordem mais geral sobre as potencialidades e as limitações acerca da existência de um imaginário futebolístico latino-americano. Primeiro, deve-se considerar os limites históricos do alcance da ideia de América Latina como uma unidade cultural, intelectual e territorial.

Tais limitações se relacionam à própria relação fragmentada dos seus países com as diversas metrópoles que a colonizaram, aguçando particularidades. Talvez um dos exemplos mais clamantes disso sejam as diferenças, no século XIX, entre as repúblicas independentes da chamada América Hispânica e o caso do Brasil, país de dimensões continentais, colonizado por Portugal e considerado a "planta exótica da América", por ter mantido o regime monárquico após a sua independência.

A configuração de uma América Latina una adquire um sentido mais convincente no decorrer do século XX, menos por suas similitudes e mais pelo crescimento de importância dos 
Estados Unidos. A reação contrastiva dos demais países situados no continente americano pode ser observada em face do poderio estadunidense, em termos políticos, econômicos e culturais.

No entanto, sugerimos que, curiosamente, a despeito de toda a penetração dos valores anglo-saxões, os esportes modernos codificados na Inglaterra vitoriana foram assumidos parcialmente pelos EUA, que não foi capaz de moldar com a mesma força seus próprios esportes na cultura esportiva da América Latina. No caso do futebol em especial, a influência se deu em via inversa, da América Latina para os Estados Unidos, com a resistência inicial estadunidense. Com o tempo, observou-se a incorporação paulatina do mundo do soccer nos Estados Unidos, a partir da popularização futebolística no mundo e na região latino-americana em particular.

Sendo assim, a relação especular do futebol na América Latina continuou sendo construída em relação a suas metrópoles europeias originárias, quer seja a influência econômica da Grã-Bretanha, quer sejam as diversas trocas culturais e futebolísticas ocorridas entre os países sul-americanos e os países latinos europeus. É certo que as Copas do Mundo foram fundamentais nesse processo, pois permitiram contrastar estilos de jogo em escala continental, mas é certo também que outras competições envolvendo selecionados nacionais foram importantes.

Em proporção análoga, a excursão de clubes europeus pela América Latina, já nos anos 1910, e a circulação de clubes latino-americanos pela Europa, a partir nos anos 1920, são igualmente importantes na conformação de tais intercâmbios e identidades.

De todas as experiências vivenciadas ao longo do século $\mathrm{XX}$, pode-se concluir que as mais importantes para se pensar identidades transnacionais no futebol, como a região ou o continente latino-americano, são os confrontos entre selecionados nacionais, com destaque para a Copa América. Esta foi criada em 1975, como ampliação do Campeonato Sul-Americano, forjado por sua vez em 1916.

Um marco dessa competição nesse imaginário ocorre em 1993, quando a Conmebol incorpora à Copa América o México, nação que então se integrara ao NAFTA, bloco econômico capitaneado pelos Estados Unidos e composto também pelo Canadá. Se do ponto de vista geográfico o México compõe oficialmente a América do Norte, sabe-se que em termos sociais, étnicos e culturais o povo mexicano encontra afinidades históricas com a chamada América Latina, colocando o país em uma posição identitária até certo ponto ambígua e fronteiriça.

Já em âmbito clubístico, a escala continental assistiu a um passo decisivo com a criação da sugestivamente intitulada Taça Libertadores da América, de 1960. A reunião de clubes sulamericanos neste torneio segue a orientação do que sucedera na Copa América e, no final da 
década de 1990, passa a convidar também equipes do México para participar da competição. Faz-se assim um motivo importante na ampliação da escala, da América do Sul para a América Latina. Esta auxilia na conformação de uma identidade latino-americana ao futebol, muito embora os países da América Central, do Caribe e das Antilhas continuem sem participar da referida competição, mais integrados à esfera de influência política, cultural e esportiva norteamericana.

Longe assim de ser um reflexo passivo do que ocorre na sociedade, os esportes modernos configuram instigantes laboratórios de observação das forças decisórias, dos sentidos políticos em jogo e dos vetores de identidade formulados coletivamente por um determinado povo, por uma determinada cultura ou por um determinado continente. $\mathrm{O}$ exemplo do futebol na América Latina é uma das expressões cabais disso.

\section{Referências}

BOMFIM, Manoel. América Latina: males de origem. Rio de Janeiro: Topbooks, 1993.

BURKE, Peter. A ideia de América Latina; Futebol versus críquete no Novo Mundo. In: O historiador como colunista. Rio de Janeiro: Civilização Brasileira, 2009.

CARDOSO, Fernando Henrique; FALETTO, Enzo. Dependência e desenvolvimento na América Latina: ensaio de interpretação sociológica. Rio de Janeiro: Civilização Brasileira, 2004.

CASTRO, Moacir Werneck de. O libertador: a vida de Simon Bolívar. Rio de Janeiro: Rocco, 1988.

DIETSCHY, Paul. L'histoire du football. Paris: Éditions Perrin, 2010.

DOSMAN, J. Edgar. Raul Prebisch: a construção da América Latina e do Terceiro Mundo. Rio de Janeiro: Contraponto, 2011.

ECHEVARRÍA, Roberto González. La glória de Cuba: história del béisbol em la isla. Madri: Editorial Colibri, 2004.

FERREIRA, Jorge (Org.). O populismo e sua história: crítica e debate. Rio de Janeiro: Civilização Brasileira, 2001.

FRYDENBERG, Julio; SAZBON, Daniel. La huelga de jugadores de 1948. In: REIN, R. (Org.). La cancha peronista: fútbol y politica (1946-1955). Buenos Aires: UNSAM Edita, 2015.

FURTADO, Celso. A economia latino-americana. São Paulo: Companhia das Letras, 2007.

GAFFNEY, Christopher Thomas. Temples of earthbound gods: stadiums in the cultural landscapes of Rio de Janeiro and Buenos Aires. Austin: University of Texas Press, 2008. 
GALEANO, Eduardo. As veias abertas da América Latina. Rio de Janeiro: Editora Paz e Terra, 1980.

GIGLIO, Sérgio Settani. COI X FIFA: a história política do futebol nos Jogos Olímpicos. São Paulo: Tese de Doutorado em Educação Física/Universidade de São Paulo, 2013.

HÉMEURY, Lucie. Le pouvoir hors-jeu? Football et péronisme em Argentine (1946-1955). In: Cahiers des Amériques latines. Paris: IHEAL, n. 74, 2014. Acesso em: 13 de maio de 2016. Disponível em https://cal.revues.org/2984

MARTÍ, José. La edad de oro. Habana: Editorial Gente Nueva, 1999.

MICELI, Sérgio. Os inventores da sociologia 'cientifica' sul-americana: Florestan Fernandes e Gino Germani. In: Vanguardas em retrocesso: ensaios de história social e intelectual do modernismo latino-americano. São Paulo: Companhia das Letras, 2012.

MORALES, André. Fútbol, identidad y poder (1916-1930). Montevideo: Editorial Fin del Siglo, 2013.

MORSE, Richard M. O espelho de Próspero: cultura e ideias nas Américas. Prefácio de Antônio Candido. São Paulo: Companhia das Letras, 1988.

MURRAY, Bill. Uma história do futebol. São Paulo: Hedra, 2000.

REIN, Raanan. (Org.). La cancha peronista: fútbol y politica (1946-1955). Buenos Aires: UNSAM Edita, 2015.

RODÓ, José Enrique. Ariel: motivos de Proteo. Caracas: Biblioteca Ayacucho, 1985.

SARMIENTO, Domingos. Facundo, ou civilização e barbárie. São Paulo: Cosac Naify, 2010.

SOMMER, Doris. Ficções de fundação: os romances nacionais da América Latina. Belo Horizonte: Editora UFMG, 2004.

TOCQUEVILLE, Alexis de. Democracy in America. New York: Alfred A. Knopf, 1985, vol. 1 .

TOLEDO, Luís Henrique de. Estilos de jogar, estilos de pensar. In: Visão de jogo: antropologia das práticas esportivas. São Paulo: Terceiro Nome, 2009.

VERÍSSIMO, Érico. Colóquios com José Vasconcelos. In: México. São Paulo: Companhia das Letras, 2013.

VITAL, Nicholas. Libertadores: paixão que nos une. São Paulo: Cultura Editora Sustentável, 2014. 